University of Windsor

Scholarship at UWindsor

8-6-2019

\title{
Neuro and hepatic toxicological profile of (S)-2,4-diaminobutanoic acid in embryonic, adolescent and adult zebrafish
}

\author{
Rosa-Maria Ferraiuolo \\ Department of Biological Sciences, University of Windsor \\ Daniel Meister \\ Department of Chemistry and Biochemistry, University of Windsor \\ Dominique Leckie \\ Department of Chemistry and Biochemistry, University of Windsor \\ Jonathan Franke \\ Department of Chemistry and Biochemistry, University of Windsor
}

Lisa A. Porter

Department of Biological Sciences, University of Windsor

See next page for additional authors

Follow this and additional works at: https://scholar.uwindsor.ca/chemistrybiochemistrypub

Part of the Biochemistry, Biophysics, and Structural Biology Commons, Biology Commons, and the Chemistry Commons

\section{Recommended Citation}

Ferraiuolo, Rosa-Maria; Meister, Daniel; Leckie, Dominique; Franke, Jonathan; Porter, Lisa A.; and Trant, John F.. (2019). Neuro and hepatic toxicological profile of (S)-2,4-diaminobutanoic acid in embryonic, adolescent and adult zebrafish. Journal of Applied Toxicology.

https://scholar.uwindsor.ca/chemistrybiochemistrypub/144

This Article is brought to you for free and open access by the Department of Chemistry and Biochemistry at Scholarship at UWindsor. It has been accepted for inclusion in Chemistry and Biochemistry Publications by an authorized administrator of Scholarship at UWindsor. For more information, please contact scholarship@uwindsor.ca. 


\section{Authors}

Rosa-Maria Ferraiuolo, Daniel Meister, Dominique Leckie, Jonathan Franke, Lisa A. Porter, and John F. Trant 
Neuro and hepatic toxicological profile of $(S)$-2,4-diaminobutanoic acid in embryonic, adolescent and adult zebrafish<smiles>NCCC(N)C(=O)O</smiles>

L-2,4-Diaminobutyric acid DABA
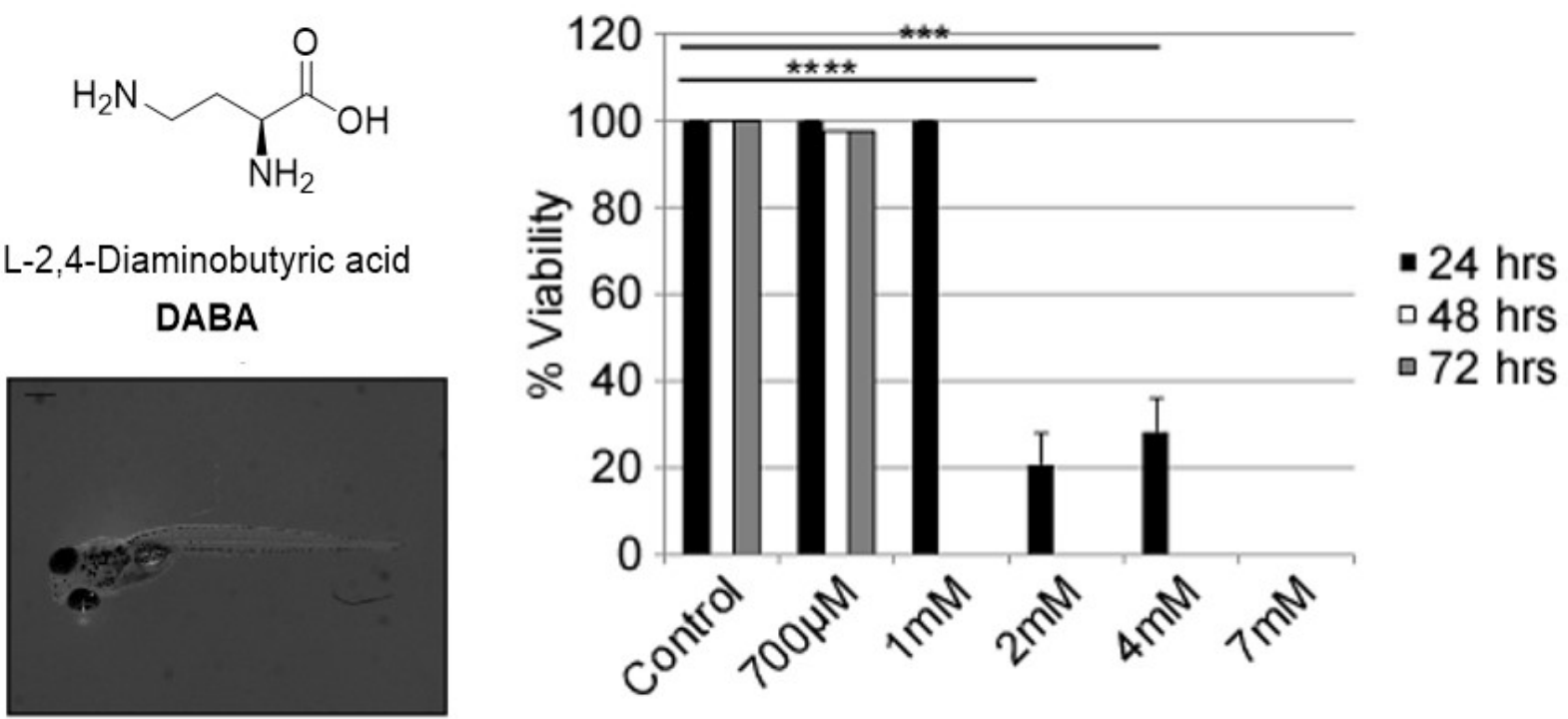

Rosa-Maria Ferraiuolo ${ }^{1}$, Daniel Meister ${ }^{2}$, Dominique Leckie ${ }^{2}$, Mohadeseh Dashti ${ }^{2}$, Jonathan Franke $^{2}$, Lisa A. Porter ${ }^{1 *}$, John F. Trant ${ }^{2 *}$

${ }^{1}$ Department of Biological Sciences, University of Windsor, Windsor, ON, N9B 3P4

${ }^{2}$ Department of Chemistry and Biochemistry, University of Windsor, Windsor, ON, N9B 3P4

\section{Notice:}

This is the peer reviewed version of the following article by Ferraiuolo et al., which has been published in final form at https://doi.org/10.1002/jat.3840. This article may be used for noncommercial purposes in accordance with Wiley Terms and Conditions for Use of Self-Archived Versions.

Ferraiuolo, R.-M., Meister, D., Leckie, D., Dashti, M., Franke, J., Porter, L. A., \& Trant, J. F. (2019). Neuro- and hepatic toxicological profile of (S)-2,4-diaminobutanoic acid in embryonic, adolescent and adult zebrafish. Journal of Applied Toxicology. Advance online publication. 


\begin{abstract}
(S)-2,4-Diaminobutanoic acid (DABA) is a noncanonical amino acid often co-produced by cyanobacteria along with $\beta$ - $N$-methylamino-L-alanine (BMAA) in algal blooms. Although BMAA is a well-established neurotoxin, the toxicity of DABA remains unclear. As part of our development of biocompatible materials, we wish to make use of DABA as both a building block and as the end-product of enzymatically-induced depolymerization; however, if it is toxic at very low concentrations, this would not be possible. We examined the toxicity of DABA using both in vivo embryonic and adult zebrafish models. At higher sub-lethal concentrations $(700 \mu \mathrm{M})$, the fish demonstrated early signs of cardiotoxicity. Adolescent zebrafish were able to tolerate a higher concentration. Post-mortem histological analysis of juvenile zebrafish showed no liver or brain abnormalities associated with hepato- or neurotoxicity. Combined, these results show that DABA exhibits no overt toxicity at concentrations (100-300 $\mu \mathrm{M})$ within an order of magnitude of those envisioned for its application. This study further highlights the low-cost and ease of using zebrafish as an early-stage toxicological screening tool.
\end{abstract}

\title{
Short Abstract
}

Zebrafish are used to evaluate the toxicity of $(S)$-2,4-Diaminobutanoic acid (DABA), a material useful for next-generation drug delivery nanoparticles. DABA is produced by cyanobacteria and is toxic at high doses, but no studies have looked at sub-mM concentrations. Below $300 \mu \mathrm{M}$ we observe no adverse effects in embryonic, adolescent or adult zebrafish. This is more than an order of magnitude above the envisioned operation concentration $(20 \mu \mathrm{M})$. Zebrafish are a useful tool for early toxicity screening. 
Keywords: diaminobutanoic acid, DABA, toxicity, zebrafish, cyanobacteria, GABA 


\section{Introduction}

DABA is a noncanonical amino acid structurally related to ornithine and lysine in having a sidechain nitrogen (Figure 1). It is produced by cyanobacteria alongside $\beta-N$-methylamino-L-alanine (BMAA) (Al-Sammak, Hoagland, Cassada, \& Snow, 2014; Fan, Qiu, Fan, \& Li, 2015), a wellknown neurotoxin (Al-Sammak, Rogers, \& Hoagland, 2015; Cox et al., 2005; Cox, Davis, Mash, Metcalf, \& Banack, 2016). As this is the major biological source of DABA and as DABA is always co-expressed with the highly toxic BMAA, determining the toxicity of DABA has not been a high priority. Nevertheless, the toxicity of DABA has remained a subject of interest and debate as different studies report substantial variability in their toxicity data (Arscott \& Harper, 1963; Beart \& Bilal, 1977; Bergenheim et al., 2006; Chen, Flory, \& Koeppe, 1972; Johnston \& Twitchin, 1977; Main \& Rodgers, 2018; O'Neal, Chen, Reynolds, Meghal, \& Koeppe, 1968). High, but localized concentrations of DABA selectively kill tumour cells but not healthy glial cells, and have been investigated as a potential co-therapy for glioblastoma (Bergenheim et al., 2006). Similar elevated concentrations of DABA have also been associated with liver toxicity and the development of brain abnormalities in rats (Chen et al., 1972; Johnston \& Twitchin, 1977; Mushahwar \& Koeppe, 1963; O'Neal et al., 1968), and chicks (Arscott \& Harper, 1963), possibly through inhibiting reuptake of GABA (Beart \& Bilal, 1977; Main \& Rodgers, 2018). High concentrations of BMAA reduced the life span in Drosophila models, decreased locomotor function, decreased learning and memory, reduced fertility in females, and delayed neurological impairment in aged adults (Zhou, Escala, Papapetropoulos, \& Zhai, 2010). All of these studies were done using relatively high concentrations (generally with $1 \mathrm{mM}$ as the lowest investigated concentration) of BMAA or DABA. The toxicity of a low dose exposure to DABA has not been systematically evaluated in 
vitro or in vivo. The toxicity of low concentrations of DABA are of interest to our groups as we propose using it as a component of a targeted, traceless, drug delivery capsule.

Targeted drug-delivery is an ever-expanding field in the biomedical sciences (Arpicco et al., 2016; Bertrand et al., 2014; Noble et al., 2014; Ulbrich et al., 2016). Current methods suffer from several drawbacks and self-immolative materials may provide a solution to this problem by allowing for complete degradation to small molecules; however, current systems are not sufficiently biocompatible (Fan and Gillies, 2015; Fan et al., 2016b; Fan et al., 2018). Selfimmolative materials are compounds that depolymerize, unit-by-unit, when exposed to a particular stimulus. The polymer we are seeking to create generates DABA as a product and we seek to evaluate its toxicity and compatibility for this application in an animal model.

Zebrafish have emerged as a highly promising screening system for environmental toxicity (A. Hill, Howard, Strahle, \& Cossins, 2003; A. J. Hill, Teraoka, Heideman, \& Peterson, 2005; Ton, Lin, \& Willett, 2006; Van den Bulck et al., 2011). For example, the related BMAA was recently tested on zebrafish to determine the impact of the compound on development and progression of amyotrophic lateral sclerosis (ALS). At low BMAA levels, only zebrafish with a familial ALS-sensitizing mutation were affected by BMAA, wildtype zebrafish remained unaffected (Powers, Kwok, Lovejoy, Lavin, \& Sher, 2017). DABA toxicity has yet to be evaluated using zebrafish. Consequently, we report the effect of exposure to varying doses of DABA on zebrafish at different stages of maturation. In this paper, we describe our investigation into the toxicity of this material and address the suitability for its use in our biomedical self-immolative polymer technology.

\section{Methods}


Synthesis of DABA. Full synthetic details on the synthesis of DABA can be found in the accompanying supporting information. Samples of synthetic DABA are available for donation upon request for collaborative purposes, although the commercial cost has dropped more than 10fold since we initiated this study.

General Experimental Protocols. Solvents were purchased from Caledon Labs (Caledon, Ontario), Sigma-Aldrich (Oakville, Ontario) or VWR Canada (Mississauga, Ontario). Other chemicals were purchased from Sigma-Aldrich, AK Scientific, Oakwood Chemicals, Alfa Aesar or Acros Organics and were used without further purification unless otherwise noted. All heated reactions were conducted using oil baths on IKA RET Basic stir plates equipped with a P1000 temperature probes. Thin layer chromatography was performed using EMD aluminum-backed silica 60 F254-coated plates and were visualized using either UV-light $(254 \mathrm{~nm}), \mathrm{KMnO}_{4}$, vanillin, Hanessian's stain, or Dragendorff's stain. Column chromatography was carried out using standard flash technique with silica (Siliaflash-P60, 230-400 mesh, Silicycle) using compressed air pressure. Standard work-up procedure for all reactions undergoing an aqueous wash involved back extraction of every aqueous phase, a drying of the combined organic phases with anhydrous magnesium sulphate, filtration either using vacuum and a sintered-glass frit or gravity through glass wool, and concentration under reduced pressure on a rotary evaporator (Buchi or Synthware) at $40{ }^{\circ} \mathrm{C} .{ }^{1} \mathrm{H}$ NMR spectra were obtained at $300 \mathrm{MHz}$ or $500 \mathrm{MHz}$, and ${ }^{13} \mathrm{C}$ NMR spectra were

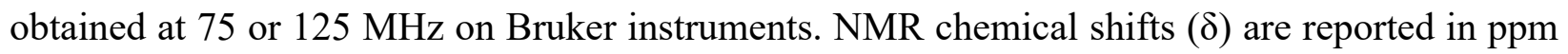
and are calibrated against solvent residual signals of $\mathrm{CHCl}_{3}(\delta$ 7.26), DMSO-d5 $(\delta 2.50), \mathrm{HDO}(\delta$ 4.79) or methanol-d3 ( $\delta 3.31)$.

Cell culture. HepG2 liver cancer cells were purchased from ATCC (American Type Culture Collection): The Global Bioresource Center. The U251 glioma cell line was a kind gift from Dr. 
Rutka (The Hospital for Sick Children Research Institute, University of Toronto). HepG2 cells were cultured in EMEM media supplemented with 10\% FBS and 30,000 units penicillin/30,000 $\mu \mathrm{g}$ streptomycin solution. U251 cells were cultured in DMEM media supplemented with 10\% FBS and 30,000 units penicillin/30,000 $\mu \mathrm{g}$ streptomycin solution. Cells were maintained under normoxic conditions $\left(5 \% \mathrm{CO}_{2}\right)$ at $37^{\circ} \mathrm{C}$.

MTT analysis. HepG2 and U251 cells were seeded at 8000 cells/well in 96-well plates. DABA was added at the indicated concentrations along with fresh media daily for 4 days. On the fifth day, $0.6 \mathrm{mg} / \mathrm{ml} \mathrm{MTT} \mathrm{reagent} \mathrm{was} \mathrm{added} \mathrm{to} \mathrm{the} \mathrm{cells} \mathrm{and} \mathrm{incubated} \mathrm{at} 37^{\circ} \mathrm{C}$ for 3 hours. The quantity of viable cells was measured by recording the changes in absorbance at $570 \mathrm{~nm}$ using a plate reading spectrophotometer.

Animal Care and Handling. Wildtype Zebrafish (Danio rerio), AB strain, were handled in compliance with local animal care regulations and standard protocols for Canada and following the University of Windsor animal care protocol \#16-04. Original colony were formed through breeding of zebrafish purchased from Pet Wise Pet Supplies store in Windsor, Ontario, Canada. Adults were housed in an Aquaneering zebrafish housing system. Adult fish were kept at $26^{\circ} \mathrm{C}$, $\mathrm{pH}$ 7.6, DO $5.1 \mathrm{mg} / \mathrm{L}$ with a 14:10 light:dark cycle. Adult fish were bred according to standard protocols (Westerfield, 1993).

Zebrafish Treatment and Analysis. Eggs were collected after fertilization and kept in E3 embryo media ( $5 \mathrm{mM} \mathrm{NaCl}, 0.17 \mathrm{mM} \mathrm{KCl}, 0.33 \mathrm{mM} \mathrm{CaCl}_{2}, 0.33 \mathrm{mM} \mathrm{MgSO}_{4}, 0.0003 \%$ Methylene Blue) at $32{ }^{\circ} \mathrm{C}$ in an incubator; $\mathrm{pH} 7$ and under a $14: 10$ light: dark cycle (hours). DABA exposure. A stock solution of $55 \mathrm{mM}$ of DABA in DI water was diluted to the indicated measured concentrations $(10 \mu \mathrm{M}, 50 \mu \mathrm{M}, 100 \mu \mathrm{M}, 300 \mu \mathrm{M}, 400 \mu \mathrm{M}, 500 \mu \mathrm{M}, 600 \mu \mathrm{M}, 700 \mu \mathrm{M}, 1 \mathrm{mM}, 2 \mathrm{mM}$, $3.5 \mathrm{mM}$, and $4 \mathrm{mM}$ ) in system water. At 18 hours post fertilization (hpf), eggs were placed in 
multiple 96-well plates, one egg per well. A total of 10 eggs per replicate (30 eggs per treatment total) were utilized to determine hatching ability. Eggs were treated with $100 \mu l$ of the indicated concentrations of DABA daily, and water and DABA was changed every 24 hours. The number of viable embryos and the number of unhatched eggs were counted and imaged using a Leica Stereoscope in this unblinded study. At 3 days post fertilization (dpf), embryos were placed one fish per well in 96-well plates and treated with $100 \mu 1$ of the indicated diluted concentrations of DABA daily. A total of 30 embryos per concentration were used; 10 embryos per replicate for each endpoint readout. Viability, health, and heartbeat were quantified and imaged. Heartbeat was measured by removing each embryo from its well in the 96-well plate and placed on a slide with $40 \mu 1$ of embryo water. Heartbeat was monitored microscopically for 1 minute intervals and recorded. Pigmentation level was determined using ImageJ software through the creation of a histogram for each embryo at each concentration. The mean pixel level was determined as an average of the pigmentation intensity for each fish (30 fish per treatment were analyzed). At both 1 month and 3 months of age, 10 fish per replicate were retrieved from a 3L stock tank and were placed in a smaller $1 \mathrm{~L}$ tank and treated with $500 \mathrm{ml}$ of the indicated concentrations of DABA daily and their viability was assessed. Daily water changes. Water changes from 96-well plates were performed using a micropipettor, waste water was disposed of in a glass container labelled for cytotoxic waste. Water changes for adult fish were performed by removing the fish from one container and transferring them into a new container with $500 \mathrm{ml}$ of fresh water dosed with the indicated concentration of DABA.

Histological Methods. Following analysis of fish at 1 month, fish were humanely sacrificed, and embedded in paraffin. Briefly, fixation of fish was done overnight in 4\% paraformaldehyde in PBS at $4^{\circ} \mathrm{C}$. Fish were then washed in PBS and embedded (embryo) or stored in 20\% EDTA (pH 8.0) 
for 10 days prior to embedding. Paraffin embedding was carried out according to standard procedures, and $8 \mu \mathrm{m}$ sections were cut. For histology, sections were dewaxed, dried and stained with Haematoxylin and Eosin (H\&E). H\&E was carried out according to manufacturer's protocol: 3-minute incubation followed by 10 -minute washing in running tap water.

Spinning Task Assay. To assess 3-month-old adult zebrafish swimming endurance, we performed the spinning task assay as previously published with minor modifications (Blazina, Vianna, \& Lara, 2013). We amended the protocol, lowering the rpm of rotation, to account for the smaller size and decreased swimming ability of our 3-month-old fish compared to either the $>8$-month fish Blazina and colleagues used, or the 5-month old fish examined by Powers and coworkers (Powers et al., 2017). Fish were tested in a $1 \mathrm{~L}$ opaque beaker containing $800 \mathrm{ml}$ of DABA diluted in system water to the required concentration. The water was heated to $26^{\circ} \mathrm{C}$ and placed on a hot plate stirrer with indicated rpm (VWR, \#12365-382). Zebrafish were acclimatized to the beaker for 10 minutes prior to testing. Three tests were performed in which zebrafish were monitored and timed as they swam against a current generated by a 9 x $50 \mathrm{~mm}$ bar spinning at $100 \mathrm{rpm}$. Swimming time was recorded using a stopwatch and was defined as the amount of time before the fish were swept up by the whirlpool current created by the stir bar.

Statistical analysis. All experiments were performed in triplicate and repeated three times. All results are expressed as the mean \pm standard error of the mean. Statistical analysis was done using the GraphPad Prism 5.01 software (GraphPad Software). Differences were compared using Oneway or Two-way ANOVA followed by Tukey multiple comparison tests to compare differences among multiple groups. Differences with $\mathrm{p}<0.05$ were considered significant.

\section{Results}


DABA does not affect human cancer cells at high concentrations. Most early stagetoxicological tests of potentially biomedically relevant materials involve easy to conduct, highthroughput cell viability assays (Patrick, 2017). Since DABA is known to influence liver and neural functions, we tested whether DABA could alter the metabolic activity of human liver (HepG2) and brain (U251) cancer cells. Cells were seeded in 96-well plates and treated over 4 days with DABA, followed by MTT analysis. Neither cell type showed any response to the addition of DABA (Figure 2); DABA appears to neither accelerate cancer cell growth or cause any cytotoxicity at these doses. To test potential effects at the organ or organism-level, we moved to examine effects in vivo using a zebrafish model.

DABA has toxicological effects in zebrafish in vivo at high concentrations. We know from the work of others that DABA has deleterious effects at very high concentrations $(>1 \mathrm{mM})$. To determine long-term health effects of DABA at lower concentrations on vertebrate viability and toxicity, we employed the Danio rerio (zebrafish) in vivo model at various life stages with exposure periods of between 2 to 7 days. After 42 hours of treatment, the hatching ability of the embryos from their chorion had become affected at the higher concentrations (Figure 3A, 400-700 $\mu \mathrm{M})$. Even after 3 days of treatment, approximately $90 \%$ of the embryos treated with $700 \mu \mathrm{M}$ did not hatch from the chorion (Figure 3A).

As the concentration of DABA was increased, developmental abnormalities were seen, including curved spine, yolk sac edema and a separated portion of the yolk sac (Figure 3B\&C). At a lower exposure concentration of $300 \mu \mathrm{M}$ DABA, $60 \%$ of fish showed signs of peri-cardial edema and yolk sac edema, while both control fish and those treated with $200 \mu \mathrm{M}$ or less of DABA 
showed no signs of edema (Figure 3B). At higher concentrations, the rate of abnormalities seen increased to $100 \%$ at $700 \mu \mathrm{M}$; including those who were manually unhatched from the chorion. This extremely sharp demarcation in the dose response curve is unusual. Embryos at the lower concentrations, $10,50,100$ and $200 \mu \mathrm{M}$ and even most of those at $300 \mu \mathrm{M}$, developed normally after hatching with no apparent ill effects from exposure to DABA.

DABA does not alter the pigmentation of zebrafish. Lack of pigmentation can be indicative of abnormal development, and over-pigmentation can be associated with cancer (Lister, 2002). This makes it a useful screening tool for gross toxicity. Following hatching, treated zebrafish were analyzed for altered pigmentation through ImageJ analysis of pictures taken of 30 different fish per treatment. These measurements and calculations determined that there is no meaningful difference in pigmentation levels ( $<4 \%$ variance), or any observable trend, regardless of DABA dose at the tested concentrations (Figure S1).

DABA affects viability of embryo and adult zebrafish. To determine viability after hatching, 6 groups of 3-dpf fish were treated with increasing concentrations of DABA for up to 7 days. Fish were evaluated for viability as well as for being stressed. Stress was defined as either having trouble breathing, swimming, or remaining upright. After one day of treatment, approximately $81 \%$ of the fish survived at $700 \mu \mathrm{M}$ while no fish survived at $3.5 \mathrm{mM}$ (Table 1). By the second day, no fish were alive at $2 \mathrm{mM}$, but no further deaths were observed at $700 \mu \mathrm{M}$ (Table 1). At the end of treatment, $700 \mu \mathrm{M}$ and $1 \mathrm{mM}$ showed similar viabilities with only $25-28 \%$ death, $3-18 \%$ stressed, and 56-68\% healthy (Table 1). However, at the lower concentration of $300 \mu \mathrm{M}$, few illeffects were observed, and the single observed death is within experimental error. 
Next, to determine the toxicity on mature fish, populations aged from 1 month (juvenile) to 3 months old (adulthood), were treated with $500 \mathrm{ml}$ of water with DABA concentrations ranging from 0 to $4 \mathrm{mM}$. The 1-month old fish treated with $700 \mu \mathrm{M}$ of DABA remained viable over all 3 days of treatment. The fish exposed to $1 \mathrm{mM}$ of DABA showed $100 \%$ viability at 24 hours; however, no fish survived after 48 hours (Figure 4A). We examined both juvenile and adult fish brains and livers following treatment to determine whether we observed any physical abnormalities. No gross difference in liver or brain structure was seen between control and treated fish using H\&E staining in any of the examined samples (representative images provided as Figure 4B). Neurotoxicity and hepatotoxicity are often associated with abnormalities in these organs during development.

The 3-month old fish responded very differently. Within 15 minutes of being treated with $4 \mathrm{mM}$ DABA $0 \%$ were viable, after 45 minutes $0 \%$ viability was seen for 1 and $2 \mathrm{mM} \mathrm{DABA}$, and after 1.5 hours $0 \%$ of fish were viable at $700 \mu \mathrm{M}$; however, $80 \%$ of fish were viable at $500 \mu \mathrm{M}$ DABA (Table 2). After 24 hours, no fish remained viable in the presence of $500 \mu \mathrm{M}$, however those exposed to DABA at either 100 and $300 \mu \mathrm{M}$ remained $100 \%$ viable. We continued to monitor these two groups of fish for an additional 72 hours. These 3-month old fish exposed to these lower levels of DABA did not suffer any deaths over the four day experiment. This viability data indicates that the ability of the zebrafish to tolerate DABA from embryo to adult changes and that adults tolerate a much lower concentration of DABA than the embryos, but that there is a dose that shows no increase in mortality. Again, there is a very sharp cut-off in viability above $300 \mu \mathrm{M}$. These data demonstrate that the ability of the fish to tolerate DABA changes from embryo to adult stage. Interestingly this occurs without direct gross effects to the cells of the liver or brain, 
suggesting that the mechanism of toxicity may not be due to hepatotoxicity or neurotoxicity as reported with higher concentrations of DABA.

Zebrafish swimming ability affected with increasing DABA concentration. To determine if a short exposure of DABA could have an effect on the swimming ability, endurance, and motility of the zebrafish, we modified the established spinning task protocol (Blazina et al., 2013). To quantify endurance, 10 zebrafish were selected from each treatment group and tested in 3 separate trials. A current was generated from a $100 \mathrm{rpm}$ stir bar in $800 \mathrm{ml}$ of system water or increasing concentrations of DABA diluted in system water. Once the zebrafish were swept up by the current and lost their orientation, the stopwatch was stopped, and the time was recorded. The control group and that subjected to the lowest DABA concentration $(100 \mu \mathrm{M})$ had identical success swimming against the current, and their latency was also longer than that of the fish subjected to higher DABA concentrations (300 and $500 \mu \mathrm{M})$ (Figure 5). These data support that short-term exposure of higher DABA concentrations impairs zebrafish motility.

Heartbeat affected after exposure to high levels of DABA. Following treatment, potential sublethal effects of DABA were investigated by measuring the average heartbeat of the zebrafish embryos at control $(0 \mu \mathrm{M}), 100 \mu \mathrm{M}, 300 \mu \mathrm{M}$, and $700 \mu \mathrm{M}$ concentrations. The average heartbeat in the studied populations of embryos did not significantly change between control and 100 or 300 $\mu \mathrm{M}$, staying consistent at 120-130 beats per minute (bpm) (Figure 6). This heartrate is consistent with typical zebrafish embryonic heart-beat rates.(De Luca et al., 2014) However, at $700 \mu \mathrm{M}$ there is a slight, but not significant, increase in bpm after $72 \mathrm{hpf}$ compared to control treated fish. After 
$96 \mathrm{hpf}$ we see a significant increase in bpm, followed by a significant decrease at $126 \mathrm{hpf}$ (Figure $6)$.

\section{Discussion and Conclusion}

Although not envisioned to be used as a drug itself, the biological impact and toxicity of DABA is of significant interest as it will form part of our drug delivery capsule. Our preliminary investigations indicate that the operational DABA concentration will be around $20 \mu \mathrm{M}$. Testing effects on cellular metabolism in vitro using human liver and brain cancer cells did not reveal any adverse effects at concentrations as high as $2 \mathrm{mM}$. This was highly encouraging, but required further testing using in vivo models. The related compound, BMAA has been shown to be incorporated into proteins in place of structurally similar L-serine (Dunlop, Cox, Banack, \& Rodgers, 2013; Glover, Mash, \& Murch, 2014) resulting in cellular toxicity, but DABA has never been detected in proteins, and does not appear to work through this mechanism (Glover et al., 2014). Instead it is reasonable to consider that toxicity might be due to its structural similarity to GABA. At high concentrations, DABA has been shown to interfere in a irreversible noncompetitive manner with carrier-mediated transport of GABA in rat synaptosomes (Levi, Rusca, \& Raiteri, 1976) acting as a reuptake inhibitor, so it is not unreasonable to believe that toxicity proceeds through a systems-level mechanism that would not be detectable using a traditional cell viability assay.

Testing systemic effects requires the use of an animal model; the high throughput nature of zebrafish: fast maturation, low cost, and small size, made them highly appealing. Using this in vivo toxicity model, we have demonstrated that DABA affects the viability in both adult and embryonic zebrafish. Cardiotoxicity becomes a concern at concentrations of $300 \mu \mathrm{M}$ or greater but 
has no observable effect below this value. The ability of zebrafish to hatch from their chorion was affected at $700 \mu \mathrm{M}$ DABA. Although beyond the scope of this study, it is possible that DABA interferes with the proteolytic enzymes required for the chorion softening for hatching to occur (Kim et al., 2004). Following hatching, morphological changes were seen in embryos treated with increasing concentrations of DABA above $300 \mu \mathrm{M}$. Developmental abnormalities were seen in the embryos including curved spine, yolk sac edema and a separated portion of the yolk sac. Again, no effect is observed below this concentration threshold. The cause for these abnormalities is unknown; however, it is consistent with the observation of developmental abnormalities in other animal systems, such as the development of crooked toes when DABA was fed to chicks at high concentrations (Arscott and Harper, 1963). DABA clearly causes developmental abnormalities at high doses for young and embryonic organisms, however, we observe no ill effects whatsoever below a threshold dose $(<300 \mu \mathrm{M})$. These concentrations $(100-300 \mu \mathrm{M})$ are approximately an order of magnitude higher than our expected therapeutic concentrations. The toxicity profile of the DABA on developing and adult zebrafish is also essential to delineating the potential safety profile of this material. Interestingly, histology showed no gross structural abnormalities in the brain or liver of fish treated with DABA, which was shown to cause brain abnormalities and liver toxicity in rats, albeit at much higher concentrations (Mushahwar \& Koeppe, 1963; O'Neal et al., 1968). Perhaps the lower dosages did not result in these abnormalities or they did not develop within this time frame. Behavioral analysis showed zebrafish swimming ability and motility was affected even after short-term exposure to DABA above the threshold indicating the possible interference with the GABA reuptake that can alter cognitive ability. As far as we are aware, this is the first report identifying a lowest observed effect concentration (LOEC) for DABA toxicity in any animal system and we cannot find any reports using such low levels of the amino acid. We observe no 
differences from control at concentrations below $300 \mu \mathrm{M}$ : our observed LOEC for DABA in zebrafish is consequently $300 \mu \mathrm{M}$ and this preliminary value is supported by the multiple independent measurements conducted.

Since the zebrafish were able to tolerate the threshold concentration and concentrations below, we were not surprised to see a steady heart-rate across the lower concentrations (0-300 $\mu \mathrm{M})$. However, as the heart-rate of fish exposed to higher concentrations of DABA were elevated, it is possible that at these low $\mu \mathrm{M}$ concentrations, toxicity occurs through some form of metabolic stress. This observation is completely consistent with the suspected GABA receptor inhibition (DiMicco, Gale, Hamilton, \& Gillis, 1979). The goal of this study was to determine whether DABA is toxic at $20 \mu \mathrm{M}$, our concentration of interest for our application. Effects are not observed at this low level. Although beyond the scope of this study, we believe that this model could prove useful for examining the mechanism of toxicity. Known GABA receptor inhibitors could be screened to determine whether the same impacts on zebrafish viability, hatching ability, heart rate and behaviour are observed as noted in this study. Further work from our group examining the toxicity will be necessary as the biomedical application development advances, especially regarding DABA's interactions with the GABA receptors and the two isoforms of glutamic acid decarboxylase (GAD65 and GAD67). However, the stage of the technology development remains too preliminary to currently justify these studies.

This project highlights the importance of integrating appropriate multi-organ models, such as the zebrafish, early in a toxicology screen. Regardless, as the effective concentrations expected to be used for our anticipated biomedical applications will be on the order of $20 \mu \mathrm{M}$, all the data collected in this study indicates that the compound deserves further development and investigation. Additional toxicity data will need to be gathered on the final formulation. This is a very early stage 
toxicity screen for the material. It both demonstrates the insufficiency of using in vitro cell-based assays alone for suspected systems-based toxicity and demonstrates that zebrafish are an inexpensive and very useful tool for early-stage toxicological evaluation of potential biomedicallyemployed chemical materials before resources are spent developing technologies that are unacceptably toxic.

\section{Funding}

The authors gratefully acknowledge financial support from the University of Windsor (JFT grant no 817074), the Natural Sciences and Engineering Research Council of Canada (JFT grant no 2018-06338; LAP grant no. 312014-2009). The authors declare no competing financial interest.

\section{Acknowledgments}

We would like to thank Dr. Rutka from the Hospital for Sick Children Research Institute at the University of Toronto for the donation of the U251 cell line and Miss Anne Semaan for technical assistance with zebrafish.

\section{References}

Al-Sammak, M. A., Hoagland, K. D., Cassada, D., \& Snow, D. D. (2014). Co-occurrence of the Cyanotoxins BMAA, DABA and Anatoxin-a in Nebraska Reservoirs, Fish, and Aquatic Plants. [Article]. Toxins, 6(2), 488-508. doi: http://doi.org/10.3390/toxins6020488

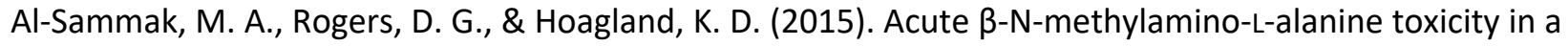
mouse model. Journal of Toxicology, 2015, Article ID: 739746. doi: http://dx.doi.org/10.1155/2015/739746

Arscott, G. H., \& Harper, J. A. (1963). Relationship of 2,5-Diamino-4,6-diketopyrimidine, 2,4Diaminobutyric Acid and a Crude Preparation of $\beta$-Cyano-L-Alanine to the Toxicity of Common and Hairy Vetch Seed Fed to Chicks. The Journal of Nutrition, 80(3), 251-254. doi: http://doi.org/10.1093/jn/80.3.251

Beart, P. M., \& Bilal, K. (1977). I-2,4-Diaminobutyric acid and the GABA system. Neuroscience Letters, 5(3), 193-198. doi: http://doi.org/10.1016/0304-3940(77)90046-5

Bergenheim, A. T., Roslin, M., Ungerstedt, U., Waldenström, A., Henriksson, R., \& Ronquist, G. (2006). Metabolic Manipulation of Glioblastoma in Vivo by Retrograde Microdialysis of L-2, 4 Diaminobutyric Acid (DAB). Journal of Neuro-Oncology, 80(3), 285-293. doi: http://doi.org/10.1007/s11060-006-9186-1 
Blazina, A. R., Vianna, M. R., \& Lara, D. R. (2013). The spinning task: a new protocol to easily assess motor coordination and resistance in zebrafish. Zebrafish, 10(4), 480-485. doi: http://doi.org/10.1089/zeb.2012.0860

Chen, C.-H., Flory, W., \& Koeppe, R. E. (1972). Variation of neurotoxicity of I- and d-2,4-diaminobutyric acid with route of administration. Toxicology and Applied Pharmacology, 23(2), 334-338. doi: http://doi.org/10.1016/0041-008X(72)90194-9

Cox, P. A., Banack, S. A., Murch, S. J., Rasmussen, U., Tien, G., Bidigare, R. R., . . Bergman, B. (2005). Diverse taxa of cyanobacteria produce $\beta$ - $\mathrm{N}$-methylamino-I-alanine, a neurotoxic amino acid. Proceedings of the National Academy of Sciences of the United States of America, 102(14), 50745078. doi: http://doi.org/10.1073/pnas.0501526102

Cox, P. A., Davis, D. A., Mash, D. C., Metcalf, J. S., \& Banack, S. A. (2016). Dietary exposure to an environmental toxin triggers neurofibrillary tangles and amyloid deposits in the brain. Proceedings of the Royal Society B: Biological Sciences, 283(1823), 20152397. doi: http://doi.org/10.1098/rspb.2015.2397

De Luca, E., Zaccaria, G. M., Hadhoud, M., Rizzo, G., Ponzini, R., Morbiducci, U., \& Santoro, M. M. (2014). ZebraBeat: a flexible platform for the analysis of the cardiac rate in zebrafish embryos. [Article]. Scientific Reports, 4, 4898. doi: http://doi.org/10.1038/srep04898

DiMicco, J., Gale, K., Hamilton, B., \& Gillis, R. (1979). GABA receptor control of parasympathetic outflow to heart: characterization and brainstem localization. Science, Di204(4397), 1106-1109. doi: http://doi.org/10.1126/science.451556

Dunlop, R. A., Cox, P. A., Banack, S. A., \& Rodgers, K. J. (2013). The Non-Protein Amino Acid BMAA Is Misincorporated into Human Proteins in Place of I-Serine Causing Protein Misfolding and Aggregation. 8(9), e75376. doi: http://doi.org/10.1371/journal.pone.0075376

Fan, H., Qiu, J., Fan, L., \& Li, A. (2015). Effects of growth conditions on the production of neurotoxin 2,4diaminobutyric acid (DAB) in Microcystis aeruginosa and its universal presence in diverse cyanobacteria isolated from freshwater in China. Environmental Science and Pollution Research, 22(8), 5943-5951. doi: http://doi.org/10.1007/s11356-014-3766-y

Glover, W. B., Mash, D. C., \& Murch, S. J. (2014). The natural non-protein amino acid N- $\beta$-methylamino-Ialanine (BMAA) is incorporated into protein during synthesis. 46(11), 2553-2559. doi: http://doi.org/10.1007/s00726-014-1812-1

Hill, A., Howard, C. V., Strahle, U., \& Cossins, A. (2003). Neurodevelopmental Defects in Zebrafish (Danio rerio) at Environmentally Relevant Dioxin (TCDD) Concentrations. Toxicological Sciences, 76(2), 392-399. doi: http://doi.org/10.1093/toxsci/kfg241

Hill, A. J., Teraoka, H., Heideman, W., \& Peterson, R. E. (2005). Zebrafish as a Model Vertebrate for Investigating Chemical Toxicity. Toxicological Sciences, 86(1), 6-19. doi: http://doi.org/10.1093/toxsci/kfi110

Johnston, G. A. R., \& Twitchin, B. (1977). Stereospecificity of 2,4-diaminobutyric acid with respect to inhibition of 4-aminobutyric acid uptake and binding. British Journal of Pharmacology, 59(1), 218219. doi: http://doi.org/10.1111/j.1476-5381.1977.tb06998.x

Levi, G., Rusca, G., \& Raiteri, M. (1976). Diaminobutyric acid: A tool for discriminating between carriermediated and non-carrier-mediated release of GABA from synaptosomes? , 1(6), 581-590. doi: http://doi.org/10.1007/BF00965600

Lister, J. A. (2002). Development of pigment cells in the zebrafish embryo. Microscopy Research and Technique, 58(6), 435-441. doi: http://doi.org/10.1002/jemt.10161

Main, B. J., \& Rodgers, K. J. (2018). Assessing the Combined Toxicity of BMAA and Its Isomers 2,4-DAB and AEG In Vitro Using Human Neuroblastoma Cells. Neurotoxicity Research, 33(1), 33-42. doi: http://doi.org/10.1007/s12640-017-9763-4 
Mushahwar, I. K., \& Koeppe, R. E. (1963). Concerning the Metabolism of d- and I- $\alpha$, $\gamma$-Diaminobutyric Acid2-C14 in Rats. Journal of Biological Chemistry, 238(7), 2460-2463. doi: None Assigned

O'Neal, R. M., Chen, C.-H., Reynolds, C. S., Meghal, S. K., \& Koeppe, R. E. (1968). The 'neurotoxicity' of I2,4-diaminobutyric acid. Biochemical Journal, 106(3), 699-706. doi: http://doi.org/10.1042/bj1060699

Patrick, G. L. (2017). An introduction to medicinal chemistry.

Powers, S., Kwok, S., Lovejoy, E., Lavin, T., \& Sher, R. B. (2017). Editor's Highlight: Embryonic Exposure to the Environmental Neurotoxin BMAA Negatively Impacts Early Neuronal Development and Progression of Neurodegeneration in the Sod1-G93R Zebrafish Model of Amyotrophic Lateral Sclerosis. Toxicological Sciences, 157(1), 129-140. doi: http://doi.org/10.1093/toxsci/kfx020

Ton, C., Lin, Y., \& Willett, C. (2006). Zebrafish as a model for developmental neurotoxicity testing. Birth Defects Research Part A: Clinical and Molecular Teratology, 76(7), 553-567. doi: http://doi.org/doi:10.1002/bdra.20281

Van den Bulck, K., Hill, A., Mesens, N., Diekman, H., De Schaepdrijver, L., \& Lammens, L. (2011). Zebrafish developmental toxicity assay: A fishy solution to reproductive toxicity screening, or just a red herring? Reproductive Toxicology, 32(2), 213-219. doi: http://doi.org/10.1016/j.reprotox.2011.06.119

Westerfield, M. (1993). The zebrafish book : a guide for the laboratory use of zebrafish (Brachydanio rerio). Eugene, OR: M. Westerfield.

Zhou, X., Escala, W., Papapetropoulos, S., \& Zhai, R. G. (2010). $\beta$-N-methylamino-L-alanine induces neurological deficits and shortened life span in Drosophila. Toxins (Basel), 2(11), 2663-2679. doi: http://doi.org/10.3390/toxins2112663 
Table 1. Viability of embryonic fish is affected with increasing DABA concentrations. Zebrafish embryos ( 3 dpf) were placed one embryo per well of a 96-well plate and treated with indicated DABA concentrations (100 $\mu 1$ per well). Concentrations of DABA was maintained both before and after hatching. Fish were monitored for viability, stress, and death after each 24-hour period. A stressed fish was defined as any fish that was having trouble breathing, swimming, or remaining upright.

\begin{tabular}{|c|c|c|c|c|}
\hline & & $\begin{array}{c}\text { Alive } \\
\text { (\%) }\end{array}$ & $\begin{array}{l}\text { Stressed } \\
(\%)\end{array}$ & $\begin{array}{c}\text { Dead } \\
(\%)\end{array}$ \\
\hline \multirow[t]{7}{*}{ Day 1} & Control & 100 & 0 & 0 \\
\hline & $100 \mu \mathrm{M}$ & 100 & 0 & 0 \\
\hline & $300 \mu \mathrm{M}$ & 92.4 & 7.6 & 0 \\
\hline & $700 \mu \mathrm{M}$ & 81.5 & 8.1 & 10.3 \\
\hline & $1 \mathrm{mM}$ & 56.1 & 26.8 & 17.1 \\
\hline & $2 \mathrm{mM}$ & 21.7 & 0 & 78.3 \\
\hline & $3.5 \mathrm{mM}$ & 0 & 0 & 100 \\
\hline \multirow[t]{6}{*}{ Day 2} & Control & 100 & 0 & 0 \\
\hline & $100 \mu \mathrm{M}$ & 100 & 0 & 0 \\
\hline & $300 \mu \mathrm{M}$ & 98.0 & 2.0 & 0 \\
\hline & $700 \mu \mathrm{M}$ & 73.6 & 14.9 & 11.5 \\
\hline & $1 \mathrm{mM}$ & 73.2 & 9.8 & 17.1 \\
\hline & $2 \mathrm{mM}$ & 0 & 0 & 100 \\
\hline \multirow[t]{5}{*}{ Day 3} & Control & 100 & 0 & 0 \\
\hline & $100 \mu \mathrm{M}$ & 100 & 0 & 0 \\
\hline & $300 \mu \mathrm{M}$ & 100 & 0 & 0 \\
\hline & $700 \mu \mathrm{M}$ & 80.4 & 6.9 & 12.7 \\
\hline & $1 \mathrm{mM}$ & 73.2 & 4.9 & 22.0 \\
\hline \multirow[t]{5}{*}{ Day 7} & Control & 100 & 0 & 0 \\
\hline & $100 \mu \mathrm{M}$ & 100 & 0 & 0 \\
\hline & $300 \mu \mathrm{M}$ & 83.1 & 13.0 & 3.9 \\
\hline & $700 \mu \mathrm{M}$ & 56.6 & 18.2 & 25.3 \\
\hline & $1 \mathrm{mM}$ & 67.8 & 4.9 & 27.3 \\
\hline
\end{tabular}


Table 2. Viability of 3-month old fish is affected with increased DABA. Adult zebrafish (3month old) were treated with increasing concentrations of $500 \mathrm{ml}$ DABA and monitored from 096 hrs (every 15 minutes for the first 1.5 hours, then at 24, 48, and 96 hours). The presented data represents selected timepoints and illustrates the dose-dependency of adult zebrafish viability.

\begin{tabular}{|c|c|c|}
\hline Concentration & Time & $\%$ Viable \\
\hline Control $(0 \mu \mathrm{M})$ & $96 \mathrm{hrs}$ & $\begin{array}{l}100 \\
100\end{array}$ \\
\hline $100 \mu \mathrm{M}$ & $\begin{array}{l}24 \mathrm{hrs} \\
96 \mathrm{hrs}\end{array}$ & $\begin{array}{l}100 \\
100\end{array}$ \\
\hline $300 \mu \mathrm{M}$ & $\begin{array}{l}24 \mathrm{hrs} \\
96 \mathrm{hrs}\end{array}$ & $\begin{array}{l}100 \\
100\end{array}$ \\
\hline $500 \mu \mathrm{M}$ & $\begin{array}{l}45 \mathrm{mins} \\
1.5 \mathrm{hrs} \\
24 \mathrm{hrs}\end{array}$ & $\begin{array}{c}100 \\
80 \\
0\end{array}$ \\
\hline $700 \mu \mathrm{M}$ & $\begin{array}{l}45 \mathrm{mins} \\
1.5 \mathrm{hrs}\end{array}$ & $\begin{array}{c}100 \\
0\end{array}$ \\
\hline $1 \mathrm{mM}$ & $\begin{array}{l}15 \text { mins } \\
45 \text { mins }\end{array}$ & $\begin{array}{c}100 \\
0\end{array}$ \\
\hline $2 \mathrm{mM}$ & $\begin{array}{l}15 \text { mins } \\
45 \text { mins }\end{array}$ & $\begin{array}{c}100 \\
0\end{array}$ \\
\hline $4 \mathrm{mM}$ & 15 mins & 0 \\
\hline
\end{tabular}

